\title{
Field-deployable diode-laser-based differential absorption lidar (DIAL) for profiling water vapor
}

\author{
S. M. Spuler ${ }^{1}$, K. S. Repasky ${ }^{2}$, B. Morley ${ }^{1}$, D. Moen $^{2}$, M. Hayman ${ }^{1}$, and A. R. Nehrir ${ }^{3}$ \\ ${ }^{1}$ National Center for Atmospheric Research, Earth Observing Lab, Boulder, CO 80307, USA \\ ${ }^{2}$ Montana State University, Electrical and Computer Engineering, Bozeman, MT 59717, USA \\ ${ }^{3}$ NASA Langley Research Center, Hampton, VA 23681, USA \\ Correspondence to: S. M. Spuler (spuler@ucar.edu)
}

Received: 26 August 2014 - Published in Atmos. Meas. Tech. Discuss.: 18 November 2014

Revised: 4 February 2015 - Accepted: 5 February 2015 - Published: 4 March 2015

\begin{abstract}
A field-deployable water vapor profiling instrument that builds on the foundation of the preceding generations of diode-laser-based differential absorption lidar (DIAL) laboratory prototypes was constructed and tested. Significant advances are discussed, including a unique shared telescope design that allows expansion of the outgoing beam for eye-safe operation with optomechanical and thermal stability; multistage optical filtering enabling measurement during daytime bright-cloud conditions; rapid spectral switching between the online and offline wavelengths enabling measurements during changing atmospheric conditions; and enhanced performance at lower ranges by the introduction of a new filter design and the addition of a wide field-of-view channel. Performance modeling, testing, and intercomparisons are performed and discussed. In general, the instrument has a $150 \mathrm{~m}$ range resolution with a $10 \mathrm{~min}$ temporal resolution; $1 \mathrm{~min}$ temporal resolution in the lowest $2 \mathrm{~km}$ of the atmosphere is demonstrated. The instrument is shown capable of autonomous long-term field operation -50 days with a $>95 \%$ uptime - under a broad set of atmospheric conditions and potentially forms the basis for a ground-based network of eye-safe autonomous instruments needed for the atmospheric sciences research and forecasting communities.
\end{abstract}

\section{Introduction}

The planetary boundary layer, the lowest part of the troposphere, contains the majority of the atmospheric water vapor (hereafter WV). The rapidly changing spatial and temporal distribution of $\mathrm{WV}$ influences dynamical and physi- cal processes that drive weather phenomena, general circulation patterns, radiative transfer, and the global water cycle. The ability to measure the WV distribution continuously within the lower troposphere has been identified as a highpriority measurement capability needed by both the weather forecasting and climate science communities. In particular, two studies by the National Research Council $(2009,2010)$ list high-resolution vertical profiles of humidity in the lower troposphere as one of the four highest-priority observations needed for a national mesoscale weather observation network. Accurate, high-resolution continuous measurements of WV remain a key observational gap for the mesoscale weather and climate process studies communities. Such observations are particularly important to the National Weather Service and other federal agencies for evaluation of forecast impact in severe weather and quantitative precipitation forecasts.

Conventional balloon-borne radiosonde soundings combined with global coverage of low-vertical-resolution state parameters via satellite-based measurements currently form the backbone of observations used for weather forecasting. However, the limited spatial and temporal resolution of these technologies is inadequate for reliable forecasts of highimpact weather events like thunderstorms. Passive remote sensors such as microwave radiometers are useful at low ranges close to the surface but in general provide low vertical resolution. The atmospheric emitted radiance interferometer (AERI) is a passive infrared remote sensing instrument that utilizes an interference technique to retrieve atmospheric emitted radiance (Turner and Löhnert, 2014; Knuteson et al., 2004a, b; Feltz et al., 2003). Starting with initial temperature 
and humidity profiles based on statistical models, an iterative solution to the radiative transfer equations is utilized to reproduce the measured atmospheric emitted radiance. This iterative solution provides the final temperature and WV profiles for clear sky conditions up to approximately $3 \mathrm{~km}$. During cloudy conditions, retrievals are sensitive to the cloud properties leading to larger errors in the temperature and WV profiles. During cloudy conditions a separate measurement of the cloud-base height is often required.

Raman lidar is an active remote sensing technique that is capable of monitoring WV in the troposphere (Goldsmith et al., 1998; Turner et al., 2002). The Raman lidar technique utilizes a high-power pulsed laser transmitter to illuminate the atmosphere. The frequency shift due to the nonlinear Raman scattering allows the scattering molecule to be identified while the intensity of the scattered signal can be used to determine the WV mixing ratio. Raman lidars typically require high laser pulse energy and large receiver aperture due to the small scattering cross section associated with nonlinear Raman scattering. Furthermore, Raman lidars typically require a calibration technique based on an ancillary measurement for quantitative $\mathrm{WV}$ retrievals.

Differential absorption lidar (DIAL) is another active remote sensing technique. It utilizes a laser transmitter capable of operating at two closely spaced wavelengths: one wavelength is located at or near the absorption feature for the molecule of interest, referred to as the online wavelength, and the other is located away from the same absorption feature, referred to as the offline wavelength. If the online and offline wavelengths are closely spaced, then the only difference between the return signals results from molecular absorption. Having a priori knowledge of the differential absorption cross section of the molecule of interest, e.g., via the HITRAN molecular spectral database (Rothman et al., 2009), the ratio of the online and offline return signals over a selected range within the atmosphere is related to the molecular number density. The advantages of the DIAL technique include no calibration or ancillary measurements and a direct retrieval of the WV number density. However, the DIAL technique requires a pulsed laser with high spectral fidelity and frequency agility, capable of operating at two separate wavelengths.

The DIAL technique has been successfully demonstrated for ground-based water vapor profiling based on injectionseeded Ti:sapphire laser systems as discussed in Ertel et al. (2005), Bösenberg and Linné (2006), Vogelmann and Trickl (2008), and Behrendt et al. (2010). Some of these instruments are capable of autonomous operation and provide a wide range of daytime measurements. However, to realize the potential societal benefits envisioned by a nationwide water vapor profiling network, a less cost prohibitive approach is needed. A significantly lower-cost profiler may be achieved by the development of diode-laser-based DIAL systems albeit with reduced performance compared to Ti:sapphirebased DIAL systems. Reliable, autonomous, low-cost trans- mitters may be enabled by diode lasers operating in the spectral region most commonly used for water vapor DIAL (700 to $950 \mathrm{~nm}$ ), and eye safety may be brought about by the inherent low pulse energies and expansion of the laser beam.

Initial modeling by Reagan et al. (1993) indicated that low pulse energy, high pulse repetition rate DIAL measurements of WV in the lower troposphere are feasible. This modeling of micropulsed DIAL instruments resulted in the first development of a diode-laser-based WV-DIAL instrument by Machol et al. (2004) that utilized a distributed feedback laser to injection-seed a tapered semiconductor optical amplifier (TSOA) to achieve the needed spectral fidelity for DIAL measurements. Machol et al. (2004) demonstrated nighttime water vapor profiles up to $2.5 \mathrm{~km}$ with $30 \mathrm{~min}$ integration periods. Building from this initial modeling and instrument development, researchers at Montana State University (MSU) developed a series of diode-laser-based WV-DIAL instruments. The first generation utilized an external cavity diode laser (ECDL) and a passively pulsed amplifier (Nehrir et al., 2009). A second-generation instrument achieved a factor of $10-20$ greater energy $(1-2 \mu \mathrm{J})$ with a pulsed dual stage TSOA in a master oscillator power amplifier (MOPA) configuration (Nehrir et al., 2011). This version provided the first demonstration of daytime water vapor measurements with a diode-laser-based DIAL. A third generation, utilizing a pair of ECDLs connected via a fiber-coupled microelectromechanical system (MEMS) switch to an improved single-stage TSOA, achieved an even greater pulse energy of $7 \mu \mathrm{J}$ (Nehrir et al., 2012). In all of these versions, the receiver utilized a commercial telescope to direct the collected light to an avalanche photodiode (APD) operating in the Geiger mode. Two narrowband filters, each with a $250 \mathrm{pm}$ full width half maximum (FWHM) bandpass, were used to filter solar background allowing clear-sky daytime measurements to approximately $3 \mathrm{~km}$.

Since the summer of 2011, the researchers at MSU and the National Center for Atmospheric Research (NCAR) have collaborated to advance and evaluate the capability of the diode-laser-based WV-DIAL technique. In 2012, the MSU third-generation WV-DIAL was modified to allow for unattended operations in a laboratory environment: replacing the external cavity diode lasers with more temperature-robust distributed Bragg reflector (DBR) lasers and expanding the beam to be eye-safe at the exit port. The redesigned transmit path for this temporary prototype used a series of large turning mirrors to reflect the expanded eye-safe beam into the receiver field-of-view (FOV) and was subject to pointing instability with environmental temperature fluctuations. Nevertheless, the modified prototype was field tested over a wide range of atmospheric conditions to evaluate its performance. The evaluation indicated that the technology was well suited for autonomous, long-term measurements of water vapor; however, as noted in Repasky et al. (2013), improvements to the instrument were needed to achieve contin- 


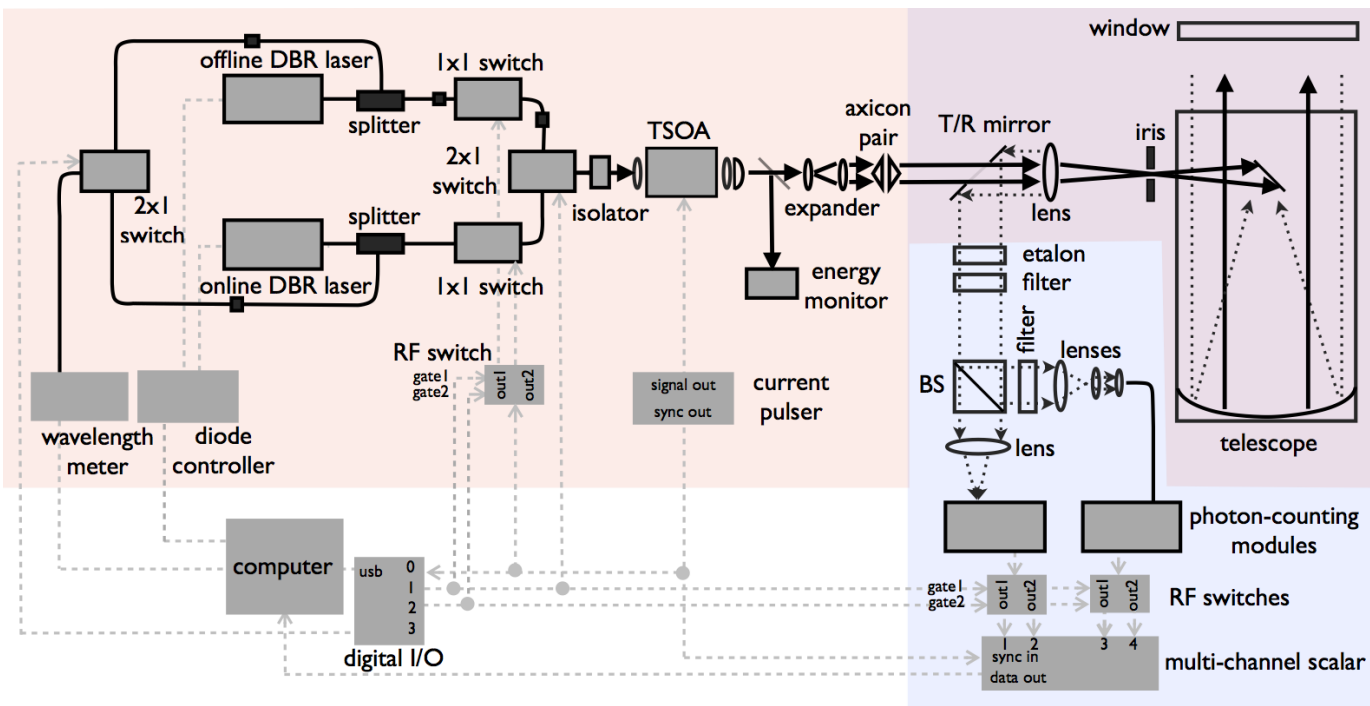

Figure 1. Schematic of the WV-DIAL system. BS is the beam splitter, T/R is transmit/receive, and I/O is input/output.

uous atmospheric coverage, particularly during bright-cloud conditions and at lower ranges.

In this paper - having addressed the needed advancement in performance given by Repasky et al. (2013) - a nextgeneration (fourth) diode-laser-based WV-DIAL is presented which is capable of autonomous long-term field operation under an expanded set of atmospheric conditions. Major improvements with respect to the older versions of the system are discussed and include

- a unique shared telescope design that allows expansion of the outgoing beam for eye-safe operation with mechanical and thermal stability

- improved performance during daytime and cloudy conditions by introducing a high-finesse etalon into the receiver optical train

- improved performance during rapidly changing atmospheric conditions through increased switching rates between the online and offline wavelengths, and

- improved performance at short range by the introduction of a near-range, wide field-of-view channel.

This paper is organized as follows. Section 2 contains a complete description of the instrument highlighting differences between the third and fourth generations. A performance model of the diode-laser-based WV-DIAL instrument is presented in Sect. 3. In Sect. 4, field data and intercomparisons are presented from when the instrument was operated at the Boulder Atmospheric Observatory (BAO) (NOAA Physical Sciences Division, 2014) during the Front Range Air Pollution and Photochemistry Experiment (NCAR Atmospheric Chemistry Division, 2014) between 1 July 2014 and 19 August 2014. Data from this field campaign are presented to demonstrate the capability of the WV-DIAL to provide continuous water vapor profiles for extended periods of time in a variety of atmospheric conditions. Furthermore, data collected during this observation period are used to validate the instrument performance model described in Sect. 3. Some brief concluding remarks are presented in Sect. 5 .

\section{Description of the field prototype}

The instrument, shown schematically in Fig. 1, utilizes a diode-laser-based MOPA-configured transmitter capable of rapid wavelength switching (red shading), a shared telescope transmitter and receiver to achieve optomechanically stable eye-safe operation (purple shading), and a multistage filtered two-channel receiver for the near- and far-range returns (blue shading). The system parameters are outlined in Table 1.

Careful absorption line selection is critical to DIAL performance (e.g., the line should be insensitive to expected atmospheric temperature variations). The line strength for the water vapor absorption feature used for the measurements presented in this paper is $S=1.477 \times$ $10^{-23} \mathrm{~cm}^{-1}\left(\mathrm{~mol} \mathrm{~cm}^{-2}\right)^{-1}$, with a ground-state energy of $E=212.2 \mathrm{~cm}^{-1}$. A complete discussion of the line section criteria and other key spectroscopic parameters for this lower troposphere a ground-based instrument is provided by Nehrir et al. (2009).

\subsection{Laser transmitter}

The laser transmitter utilizes two DBR laser diodes (Photodigm, Inc., PH828DBR100TS): one operating at the online wavelength $(828.2 \mathrm{~nm})$ and the other operating at the offline wavelength $(828.3 \mathrm{~nm})$ These lasers operate in the continu- 
Table 1. Instrument parameter list.

\begin{tabular}{|c|c|}
\hline Seed lasers & Two DBR diode lasers (electrically pumped with $140 \mathrm{~mA}$, nominal) \\
\hline Amplifier & Single-stage TSOA (electrically pumped with $10 \mathrm{~A}, 1 \mu \mathrm{s}$ pulses) \\
\hline Transmitted pulse duration & $900 \mathrm{~ns}$ \\
\hline Transmitted pulse energy & $5 \mu \mathrm{J}$ \\
\hline Pulse repetition rate & $9 \mathrm{kHz}$ \\
\hline Max range & $16.5 \mathrm{~km}$ \\
\hline Laser wavelength & $830 \mathrm{~nm}$ \\
\hline Transmitted beam $M^{2}$ & $2 \times 6$ \\
\hline Laser divergence & $56 \mu \mathrm{rad}$ \\
\hline Transmitted beam diameter & $114 \mathrm{~mm}$ effective (axicon shaped to $180 \mathrm{~mm}$ with $70 \mathrm{~mm}$ hole) \\
\hline Lidar design geometry & $\mathrm{T} / \mathrm{R}$ partitioned shared telescope \\
\hline Telescope type & $f / 3$ Newtonian \\
\hline Telescope diameter & $406 \mathrm{~mm}$ \\
\hline Effective receiver collection area & $935 \mathrm{~cm}^{2}$ \\
\hline Field-of-view & $115 \mu \mathrm{rad}$ (far channel), $451 \mu \mathrm{rad}$ (near channel) \\
\hline Detector active area diameter & $\begin{array}{l}105 \mu \mathrm{m} \text { diameter fiber-coupled (far channel), } \\
180 \mu \mathrm{m} \text { diameter free space (near channel) }\end{array}$ \\
\hline Photon-detector module & $20 \mathrm{~ns}$ dead time $\left(<5 \mathrm{Mcs}^{-1}\right)$, saturation at $40 \mathrm{Mcs}^{-1}$ \\
\hline Quantum efficiency of detector & 0.45 \\
\hline Efficiency of the receiver & 0.23 (far channel), 0.04 (near channel) \\
\hline Daylight blocking filters & $\begin{array}{l}750 \mathrm{pm} \text { two-cavity interference filter (far and near) } \\
2.5 \mathrm{pm} \text { fringe etalon (far and near) } \\
500 \mathrm{pm} \text { two-cavity interference filter (far only) }\end{array}$ \\
\hline Combined filter width & $20 \mathrm{pm}$ (near), $14 \mathrm{pm}$ (far) \\
\hline Online-offline switch speed (type) & $0.3 \mu \mathrm{s}($ ElectroOptic) \\
\hline Online-offline switching rate & $100 \mathrm{~Hz}$ \\
\hline Photon counting & Multichannel scaler card (four-channel output) \\
\hline Data collection duty cycle & $100 \%$ \\
\hline Data collection rate & $1.1 \mathrm{~s}$ \\
\hline Water vapor averaging time & $1-10 \min ($ typical) \\
\hline Online and offline wavelength locking & $\begin{array}{l} \pm 0.05 \mathrm{pm} \\
\text { (absolute accuracy } \pm 0.2 \mathrm{pm} \text { with } \pm 0.03 \mathrm{pm} \text { repeatability) }\end{array}$ \\
\hline
\end{tabular}

ous wave (cw) mode, produce up to $80 \mathrm{~mW}$ of power, and have a measured linewidth less than $1 \mathrm{MHz}$. Previous horizontal path, hard target spectral purity measurements indicate that the spectral purity of the pulsed laser transmitter exceeds $99.96 \%$ as discussed in Nehrir (2011). The output from each diode is collimated using an aspheric lens and passes through a Faraday isolator to prevent unwanted feedback from affecting the power output and spectral stability. This seed laser light is then fiber coupled to allow for splitting and switching prior to pulsed amplification in the TSOA.

The third-generation WV-DIAL instrument used a fibercoupled MEMS switch, which exhibited a $1 \mathrm{~ms}$ 10/90 switching time as discussed in Nehrir et al. (2012), to alternate between the online and offline wavelength. The data acquisition system utilized a single channel of a four-channel scaler photon-counting card which had two buffers to allow for continuous read and write operations to occur. To avoid mixing the signals within the data acquisition system, one laser frequency was transmitted for $3 \mathrm{~s}$, followed by a $3 \mathrm{~s}$ dead time when the wavelength switch was changed, and then the other laser frequency was transmitted for $3 \mathrm{~s}$. This switching method worked well, but it created several performance limitations. First, the dead time resulted in a $60 \%$ duty cycle (i.e., the reported water vapor integration time of 20 min was equivalent to a 33 min temporal resolution). Second, wavelength switching on timescales of several seconds can result in errors due to decorrelation between the online and offline signals from fluctuations in the backscatter coefficient, as discussed in Wulfmeyer and Walther (2001a). Therefore, the next-generation instrument was designed to use faster optical switches (Agiltron, NanoSpeed); these electro-optic-based components are capable of $100 \mathrm{~ns}$ 90/10 switching times. The new switching method - combined with radio frequency $(\mathrm{RF})$ switches in the receiver (details in the receiver section to follow) - allows the instrument to run at nearly $100 \%$ duty cycle and thereby enables a significant improvement in temporal resolution. A pair of fast optical switches are used for each wavelength: a $1 \times 1$ switch is used to turn on the cw seed lasers only when the TSOA current is applied and a $2 \times 1$ switch is used to alternate the modulated online and offline seed signals to the TSOA at high repetition rates. The switches were connected as shown in Fig. 1. This 
two-stage optical switch arrangement provides $40 \mathrm{~dB}$ isolation between the online and offline (each switch has $-20 \mathrm{~dB}$ crosstalk) to maintain a high spectral purity in the transmitted pulses. The instrument has typically operated with the two wavelengths interleaved at 60 to $100 \mathrm{~Hz}$.

The TSOA stage for this instrument is the same as in its third-generation predecessor (Nehrir et al., 2012). The output of the seed laser delivery fiber is collimated and passed through a Faraday isolator. A half-wave plate is used to set the polarization needed by the TSOA. This light is incident on an aspheric lens and focused into a $4 \mathrm{~mm}$ long TSOA (Eagleyard Photonics, EYP-TPA-0830) used to amplify and pulse the laser transmitter. The TSOA is driven with a commercial pulsed current driver (Directed Energy, Inc., PCX7420) with a programmable pulse duration, pulse repetition rate, and peak pulse current. Standard setting for this instrument used a pulse current of $10 \mathrm{~A}$ with a $1.1 \mu$ s pulse duration and a $9 \mathrm{kHz}$ pulse repetition frequency. The pulsed current driver is used as the master clock for the DIAL instrument. The leading edge of the current pulse to the TSOA is used to simultaneously trigger the $1 \times 1$ switches, the I/O digital counter (which in turn triggers the $2 \times 1$ switch and RF switches in the receiver ), and the multichannel scaler card (MCS). Therefore, although a $1.1 \mu$ s current pulse is applied to the TSOA, the resulting amplified laser pulse has a $900 \mathrm{~ns}$ duration due to the $200 \mathrm{~ns}$ rise time of the $1 \times 1$ switch driver. Because of the astigmatic geometry of the output facet of the TSOA, the output requires a beam-shaping pair of lenses (spherical and cylindrical) to achieve a nominally circular collimated beam. Following the collimation optics, a window is used to direct approximately $4 \%$ of the light to a photodetector to monitor the average output power from the laser transmitter.

\subsection{Shared telescope}

The fourth-generation instrument uses a shared telescope (400 mm diameter, $f / 3$ Newtonian) for transmission and receiving. This provides the system greater stability and offers a method for larger beam expansion for eye safety. The design is a factor 20 times more optomechanically stable than the preceding co-axial design because the beam is expanded by the telescope after the transmit mirror. Although there are examples of shared telescopes in the lidar community, they often illuminate the entire primary mirror to expand the beam with the telescope and in the process lose light that is blocked by the secondary mirror. Because this system uses a lowpower laser transmitter, the spatial distribution of the outgoing beam is shaped for efficient transmission through the shared telescope. Starting with the collimated output from the TSOA, the laser transmitter is expanded using a twotimes beam expander. The beam is incident on a matched pair of conical (axicon) lenses to create a collimated annular beam with an outside diameter dependent on the axicon spacing and wedge angle, while the inside diameter is con- trolled by the incident beam diameter. The beam is not expanded to the full diameter of the telescope - unlike many shared telescope designs in the lidar community which use a polarization $\mathrm{T} / \mathrm{R}$ switch to separate the transmit from the receive path - but instead use an annular mirror to divide the telescope primary. This provides better isolation between transmit and receive paths. The annular-shaped beam passes through a $10 \mathrm{~mm}$ hole bored through the center of an elliptic mirror and is then incident on a lens with a $60 \mathrm{~mm}$ focal length. The $f$ number for the laser transmitter beam matches the $f$ number of the telescope to maximize efficiency of the lens, to avoid vignetting, and to collimate the outgoing laser beam as it exits the telescope. The transmitted beam is approximately $180 \mathrm{~mm}$ in diameter (roughly half the diameter of the primary mirror) with a $70 \mathrm{~mm}$ hole; it clears the secondary mirror as it exits the telescope and minimizes losses in the laser transmitter pulse energy. In this manner, the inner half of the telescope is used to expand the outgoing laser transmitter pulse for eye-safe operation while the outer half of the telescope is used to collect the scattered return signal.

The transmitted beam for this instrument was designed to be eye safe at the exit of the telescope as defined by standard Z136.1-2007 given by the American National Standard Institute (2007). As discussed in Nehrir et al. (2012) the second- and third-generation MSU WV-DIAL instruments were not eye-safe at the exit aperture. It is imperative for an autonomous lidar system to be eye-safe at all ranges to allow for unattended operation. It is also an enabling feature for a network of instruments which would require oversight and compliance with Federal Aviation Administration. The ANSI regulation sets the single-pulse maximum permissible exposure (MPE) for a $1 \mu \mathrm{s}$ duration pulse at the $830 \mathrm{~nm}$ wavelength at $900 \mathrm{~nJ} \mathrm{~cm}^{-2}$ (from Table $5 \mathrm{a}$ in Z136.1-2007). A repetitively pulsed lidar system must be less than both the multiple energy and multiple power MPEs, which for this system, operating at the $9 \mathrm{kHz}$ repetition rate, is $52.0 \mathrm{~nJ} \mathrm{~cm}^{-2}$ and $0.47 \mathrm{~mW} \mathrm{~cm}^{-2}$, respectively. For eye safety at the exit port (i.e., a $0 \mathrm{~m}$ range MPE), the TSOA amplified beam was expanded two times, shaped with an axicon pair, and expanded an additional 20 times with the shared receiver optics. The $1 / e$ diameter was measured before the axicons and telescope expansion to be $5.7 \mathrm{~mm}$. After the 20-times telescope expansion, the transmitted beam has an effective diameter of $114 \mathrm{~mm}$ ( $180 \mathrm{~mm}$ diameter with a $70 \mathrm{~mm}$ hole.) The entire transmitted beam area was checked with a $1 \mathrm{~cm} \times 1 \mathrm{~cm}$ square calibrated detector to verify that the $0.47 \mathrm{~mW} \mathrm{~cm}^{-2}$ MPE was not exceeded.

\subsection{Optical receiver}

Light scattered in the atmosphere is collected by the telescope and is incident on the $60 \mathrm{~mm}$ focal length lens which collimates the light collected from infinity. The received light is then incident on the elliptic mirror with the bored hole. This mirror only collects light from a diameter of greater than 
(a)

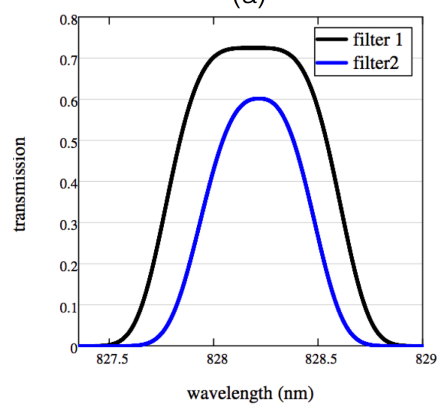

(b)

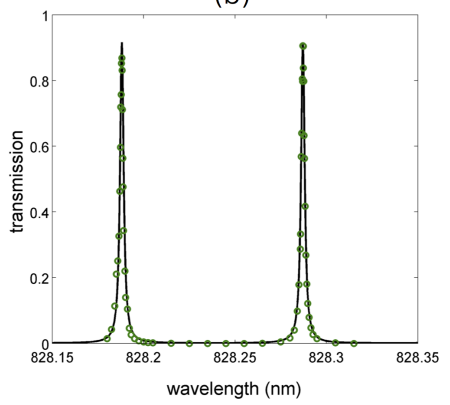

(c)

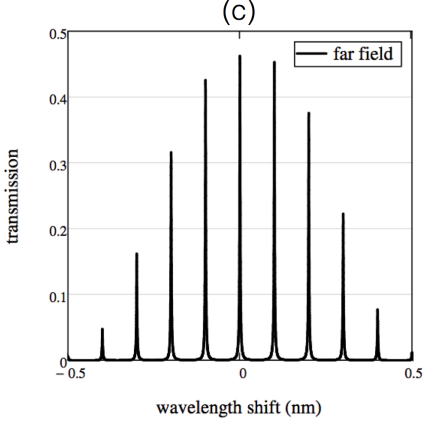

Figure 2. The multistage optical filtering enabling measurement of water vapor during daytime bright-cloud conditions. (a) The interference filter transmission as a function of wavelength: the solid black (blue) line is a fit to the measured filter transmission for the FWHM bandpass of $750 \mathrm{pm}(500 \mathrm{pm})$. A double cavity design was used for both filters to provide a more flat passband. The wider filter is common to both the near- and far-range channels while the narrower filter is used only in the far-range channel. (b) The etalon transmission as a function of wavelength; the green circles represent measured values while the solid black line represents a fit. (c) The combined passband for the far-range channel including both interference filters and the etalon.

$200 \mathrm{~mm}$ at the primary mirror of the telescope, providing excellent isolation from the transmitted beam. The ability of the receiver to discriminate signal photons against a bright background requires a state-of-the-art multistage filter that suppresses the background while minimally affecting the signal. This is a difficult task during daytime and cloudy conditions where the high background signal can easily saturate the photon-counting detector. For this instrument, the background suppression is achieved through a combination of interference filters and an etalon. The passband of the filters, the etalon, and the combined far-range filter-etalon passband are shown in Fig. 2. Figure 2a shows the transmission curve for the $500 \mathrm{pm}$ (blue) and $750 \mathrm{pm}$ (black) FWHM bandpass filters. The transmission of the $750 \mathrm{pm}$ filter remains relatively constant between 828.2 and $828.4 \mathrm{~nm}$ to both maximize the online and offline throughput and minimize angle tuning effects for the filter transmission at lower ranges that can affect the accuracy of the number density retrieval as discussed in Nehrir et al. (2009) and Wulfmeyer and Bösenberg (1998). Figure $2 \mathrm{~b}$ shows the etalon transmission measurements and a fit to the data based on

$T_{\text {etalon }}=\frac{(1-R)^{2}}{1+R^{2}-2 R \cos \theta}$,

where $R$ is the etalon mirror reflectivity and $\theta=4 \pi \frac{n L}{\lambda}$ is the round-trip phase accumulation. The free spectral range (FSR) of the etalon is related to the optical cavity spacing by $\mathrm{FSR}=\frac{c}{2 n L}$ and was measured to be $0.0994 \mathrm{~nm}(43.3 \mathrm{GHz})$. The etalon was designed to allow transmission of the online and offline radiation in adjacent cavity modes. The finesse $(F)$ of the etalon is related to the mirror reflectivity by $F=\frac{\pi \sqrt{R}}{1-R}$, yielding a finesse of $F=43$. Figure 2c shows the combined passband for the far-range receiver channel including both interference filters and the etalon.

The etalon (manufactured by Light Machinery) is housed in a temperature-controlled mount that integrates with the tube assembly housing of the receiver optics. A change in temperature of $22.4^{\circ} \mathrm{C}$ is needed to tune the etalon through a full free spectral range. The operating temperature of the etalon is controlled via a thermoelectric cooler using a commercial temperature controller with a temperature stability of $0.01{ }^{\circ} \mathrm{C}$. The operating temperature of the etalon is adjusted to be resonant with the transmitted wavelengths. A plot of the resonant wavelength as a function of temperature is shown in the left panel of Fig. 3. The black circles represent measured values and the red line represents a linear fit showing a temperature tuning rate of $\mathrm{d} \lambda / \mathrm{d} T=0.00441 \mathrm{~nm}^{\circ} \mathrm{C}^{-1}$. A plot of the cavity transmission as a function of finesse is shown on the right panel of Fig. 3. The locking stability of the injection-seeding laser and the temperature stability of the etalon affects the etalon transmission. The effects of the locking stability on the cavity transmission can be modeled using the above equation with $\theta=\pi \frac{\Delta \lambda}{\operatorname{FSR}_{\lambda}}$, where $\Delta \lambda$ is the detuning from the resonant peak in wavelength and $\mathrm{FSR}_{\lambda}$ is the free spectral range in wavelength. The temperature stability of the etalon can be modeled using the measured temperature tuning rate, $\mathrm{d} \lambda / \mathrm{d} T$, through the above equation as well with $\theta=2 \pi \frac{\mathrm{d} \lambda / \mathrm{d} T \Delta T}{\mathrm{FSR}_{\lambda}}$, where $T=0.01{ }^{\circ} \mathrm{C}$ is the temperature stability for the etalon.

Following the filters, $90 \%$ of the received light is directed to a narrow FOV fiber-coupled detector module (Excelitas, SPCM-AQRH-13-FC) and 10\% of the light to a free space receiver (Excelitas, SPCM-AQRH-13) using a beam-splitting cube (as shown in Fig. 1). The simplicity and relatively low cost of these commercial off-theshelf (COTS) single-photon-counting modules, coupled with the low-power diode-laser-based transmitter, makes them a good choice for the instrument - especially since the end goal of this research is to develop a low-cost, reliable device that would participate in a national-scale network. The light transmitted through the beam-splitting cube is incident on a $20 \mathrm{~mm}$ focal length lens focusing it onto a free-space 

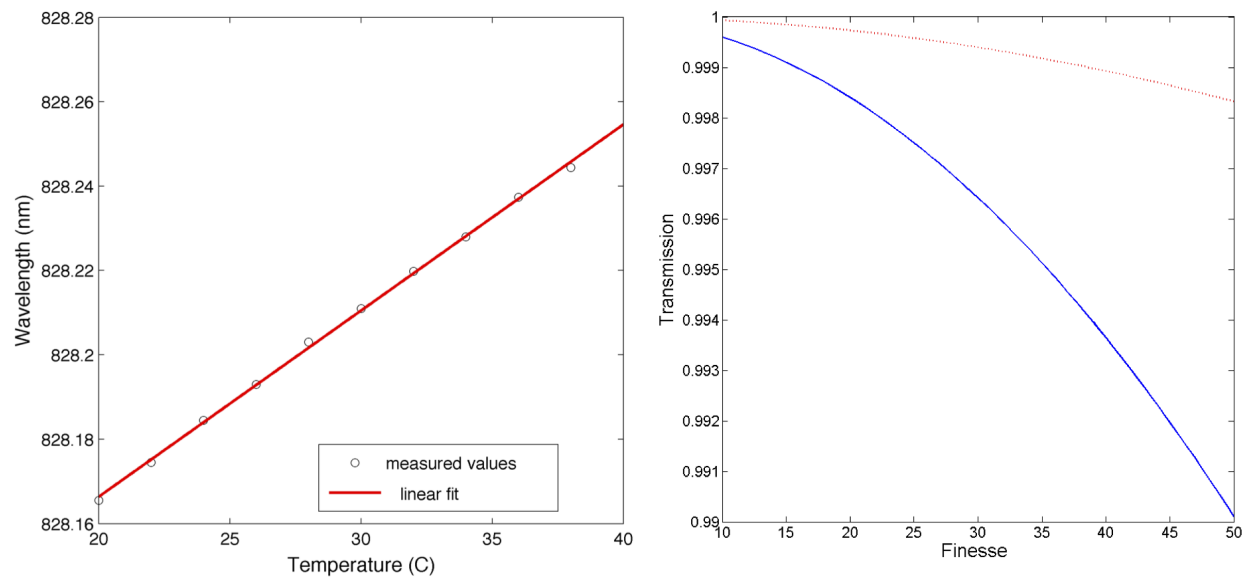

Figure 3. Etalon temperature tuning and stability. Left panel: resonant wavelength as a function of etalon operating temperature. The black circles represent measured values while the red line is a linear fit yielding a temperature tuning rate of $0.0041 \mathrm{~nm}{ }^{\circ} \mathrm{C}^{-1}$. Right panel: the cavity transmission as a function of finesse for a locking stability of $0.0002 \mathrm{~nm}$ (solid blue line) and a temperature stability of $0.01{ }^{\circ} \mathrm{C}(\mathrm{dotted}$ red line).

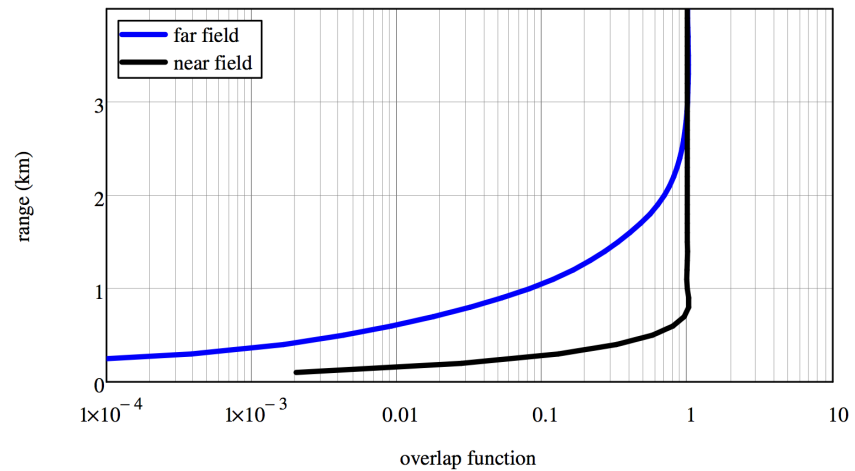

Figure 4. Overlap function for the far- and near-range receiver channels calculated from an optical model of the instrument.

avalanche photodiode. The active area of the APD acts as the field stop resulting in a $451 \mu \mathrm{rad}$ field-of-view. The light reflected from the beam-splitting cube passes through an interference filter with a 500 pm FWHM passband (passband is shown as the blue curve in Fig. 2a). The diameter of the beam is reduced approximately four times with a beam-reducing pair of optics ( $80 \mathrm{~mm}$ and $19 \mathrm{~mm}$ focal length) to not exceed the numerical aperture (NA) of the fiber, then focused with an $11 \mathrm{~mm}$ focal length lens into an multimode optical fiber with a $105 \mu \mathrm{m}$ core diameter and a NA of 0.22 . The optical fiber acts as the field stop producing a FOV of $115 \mu \mathrm{rad}$. The optical fiber guides the received light to a fiber-coupled APD.

For each detector module, full overlap occurs when the image of transmitted beam diameter is less than the diameter of the field stop. As shown in Fig. 4, the narrow field-of-view receiver (far-range channel) has full overlap at ranges greater than $2.75 \mathrm{~km}$, whereas the wide field-of-view receiver (or near-range channel) achieves full overlap at approximately
$700 \mathrm{~m}$. The collected light has a $r^{-2}$ dependence; therefore the near-range channel will have a larger signal at low ranges. However, it will also have substantially higher noise during daytime as it collects 16 times more background light compared to the far channel (solid angle $\propto \mathrm{FOV}^{2}$ ). Thus only the lowest range gates of the wide field-of-view channel are useful during daytime. As discussed later, this receiver channel is most useful when operating the instrument at short temporal and spatial resolutions (e.g., $1 \mathrm{~min}$ and $75 \mathrm{~m}$, respectively).

\subsection{Data acquisition and post-processing}

The output signal from the photon-detection modules are connected to RF switches as shown in Fig. 1. The RF switch is used to separate the signals generated from the photoncounting module between the online and offline transmitted laser pulses so as to eliminate the buffer crosstalk problem previously mentioned for the third-generation system. A digital I/O counter tracks the number of pulses from the currentpulse driver and sends a transistor-transistor logic statechange to the pair of RF switches after a prescribed number of pulses are counted at each wavelength. In the standard configuration, the current pulse generator operates at $9 \mathrm{kHz}$, so there are 150 pulses at each wavelength with $60 \mathrm{~Hz}$ switching. The outputs of each RF switch are connected to two separate channels on the MCS. For near- and far-range all four channels of a $20 \mathrm{MHz}$ MCS (Sigma Space Corporation) are used. 10000 samples are accumulated with a bin duration of $500 \mathrm{~ns}$ and 220 bins for a maximum range of $16.5 \mathrm{~km}$ with $1.1 \mathrm{~s}$ acquisition time. The approximate $1 \mu \mathrm{s}$ pulse duration is over-sampled by the MCS, yielding two data points per $150 \mathrm{~m}$, which corresponds to a sampled vertical range resolution of $75 \mathrm{~m}$. The summing of these $75 \mathrm{~m}$ bins is performed 
Table 2. Model atmosphere parameters used to calculate the performance.

\begin{tabular}{ll}
\hline Daytime sky radiance & $1.15 \times 10^{-3} \mathrm{~W} \mathrm{~cm}^{-2} \mu \mathrm{m}^{-1} \mathrm{sr}^{-1}$ \\
Nighttime sky radiance & $5 \times 10^{-5} \mathrm{~W} \mathrm{~cm}^{-2} \mu \mathrm{m}^{-1} \mathrm{sr}^{-1}$ \\
Aerosol lidar ratio & $50 \mathrm{sr}$ \\
Molecular lidar ratio & $8 / 3 \pi \mathrm{sr}$ \\
Molecular backscatter coefficient & Fig. 5 (left panel) \\
Aerosol backscatter coefficient & Fig. 5 (left panel). Data from Pike and Sabatier (2001). Wave- \\
& length scaled lower decile values from Table 4 on page 944. \\
Water vapor concentration profile & Fig. 5 (right panel). Data from Wulfmeyer and Walther (2001b). \\
&
\end{tabular}

during post-processing where two bins are grouped together to yield a $150 \mathrm{~m}$ range resolution for the DIAL measurement.

Note that the large number of scattered photons from the outgoing pulse prohibits measuring the atmospheric return during the initial $1.1 \mu$ s (i.e., while the current pulse is applied to the TSOA). Therefore, in the standard operational configuration the lowest usable range gate is $225 \mathrm{~m}$. However, the current driver is easily reconfigurable; thus, for example, if it were programmed for a $500 \mathrm{~ns}$ duration pulse, the lowest usable gate could be reduced to $75 \mathrm{~m}$ range. The amplified laser pulse would be $300 \mathrm{~ns}$ in duration with roughly one-third of the energy per pulse.

\section{Model performance of a photon-counting DIAL}

In the following, we consider a photon-counting DIAL system. The precision of the water vapor measurement can be estimated by the propagation of independent errors in the DIAL equation given by

$n_{\mathrm{wV}}(r)=\frac{1}{2 \Delta r\left(\sigma_{\mathrm{on}}(r)-\sigma_{\mathrm{off}}(r)\right)} \ln \left[\frac{N_{\mathrm{on}}(r)}{N_{\mathrm{on}}(r+\Delta r)} \frac{N_{\mathrm{off}}(r+\Delta r)}{N_{\mathrm{off}}(r)}\right]$,

where $n_{\mathrm{wv}}$ is the number density of water vapor, $\Delta r$ is the range bin size, $\sigma$ is the absorption cross section at the online and offline wavelength (subscripts on and off, respectively), and $N$ is number of online and offline (subscripts on and off, respectively) backscattered photons received.

The number of signal counts is given by

$$
\begin{aligned}
& N_{\mathrm{s}}(r, \lambda)=\frac{E \lambda}{2 h} \frac{A_{\mathrm{r}}}{r^{2}}\left(\beta_{\mathrm{a}}(r)+\beta_{\mathrm{m}}(r)\right) \eta_{\mathrm{r}} \eta_{\mathrm{d}} O(r) \\
& {\left[\exp \left(-2 \int_{0}^{r^{\prime}}\left(\alpha_{\mathrm{a}}(r)+\alpha_{\mathrm{m}}(r)+(\sigma(r, \lambda)) n_{\mathrm{wv}}\right) \mathrm{d} r^{\prime}\right],\right.}
\end{aligned}
$$

where $E$ is the pulse energy of the laser, $\lambda$ is the laser wavelength, $h$ is the Planck constant, $A_{\mathrm{r}}$ is the area of the receiver telescope, $\beta$ is the backscatter coefficient for aerosol and molecular (subscripts a and $\mathrm{m}$, respectively), $\eta$ is the efficiency of the receiver and detector (subscripts $r$ and d, respectively), $O(r)$ is the overlap function, and $\alpha$ is the extinction coefficient of the aerosol, molecular and water vapor (subscripts a, and $\mathrm{m}$, respectively).
The number of background counts is given by

$N_{\mathrm{B}}=S_{\mathrm{b}} \Omega_{\mathrm{r}} \Delta_{\mathrm{f}} A_{\mathrm{r}} \eta_{\mathrm{r}} \eta_{\mathrm{d}} \frac{\lambda}{h c}$,

where $S_{\mathrm{b}}$ is the sky radiance, $\Omega_{\mathrm{r}}$ is the receiver field-of-view solid angle, $\Delta_{\mathrm{f}}$ is filter bandpass width, $A_{\mathrm{r}}$ is the area of the receiver telescope, $\eta$ is the efficiency of the receiver and detector, and $c$ is the speed of light.

The DIAL random relative error is given by

$$
\begin{aligned}
& \frac{\sigma_{n}}{n_{w v}}(r)=\frac{1}{2 \Delta r\left(\sigma_{\mathrm{on}}(r)-\sigma_{\mathrm{off}}(r)\right) n_{\mathrm{Wv}}}\left(\frac{1}{m k}\right)^{0.5} \\
& \times\left[\frac{N_{\mathrm{S} . o n}(r)+N_{\mathrm{B}}}{N_{\mathrm{S} . o n}(r)^{2}}+\frac{N_{\mathrm{S} . o n}(r+\Delta r)+N_{\mathrm{B}}}{N_{\mathrm{S} . o n}(r+\Delta r)^{2}}\right. \\
& \left.+\frac{N_{\mathrm{S} . \text { off }}(r)+N_{\mathrm{B}}}{N_{\mathrm{S} . \text { off }}(r)^{2}}+\frac{N_{\mathrm{S} . \text { off }}(r+\Delta r)+N_{\mathrm{B}}}{N_{\mathrm{S} . o f f}(r+\Delta r)^{2}}\right]^{0.5},
\end{aligned}
$$

where $m$ is the number of range bins averaged, $k$ is the number of samples/profiles averaged for the online wavelength (assumes a $50 \%$ duty cycle), $\sigma_{\text {on }}$ is the online absorption cross section, $\sigma_{\text {off }}$ is the offline absorption cross section, and $\Delta r$ is the range bin size. It should be noted that the equation assumes the times of transmitting and receiving the online and offline wavelengths are equal. However, asynchronous wavelength switching - spending more time transmitting and receiving the online wavelength - could provide an enhancement in performance.

This random-error equation can be used to provide performance estimates for a diode-laser-based WV-DIAL. The performance estimate includes the instrument parameters given in Table 1, the atmospheric parameters summarized in Table 2, overlap functions shown in Fig. 4, and the backscatter coefficients and water vapor number density shown in Fig. 5.

The expected instrument performance for day and night conditions with a $10 \mathrm{~min}$ integration time and $150 \mathrm{~m}$ range resolution, when tuned to a two-way online column optical depth (OD) of 1.5, is shown in Fig. 6. Using $10 \%$ error as a target, the maximum range of the instrument is expected to vary from about $2.5 \mathrm{~km}$ to $3.25 \mathrm{~km}$ between day to night, respectively. At these spatial and temporal resolutions, the near channel would provide a redundant measurement extending to about $2.25 \mathrm{~km}$ range at night and about $1.5 \mathrm{~km}$ range during the day except during periods of bright clouds where the 

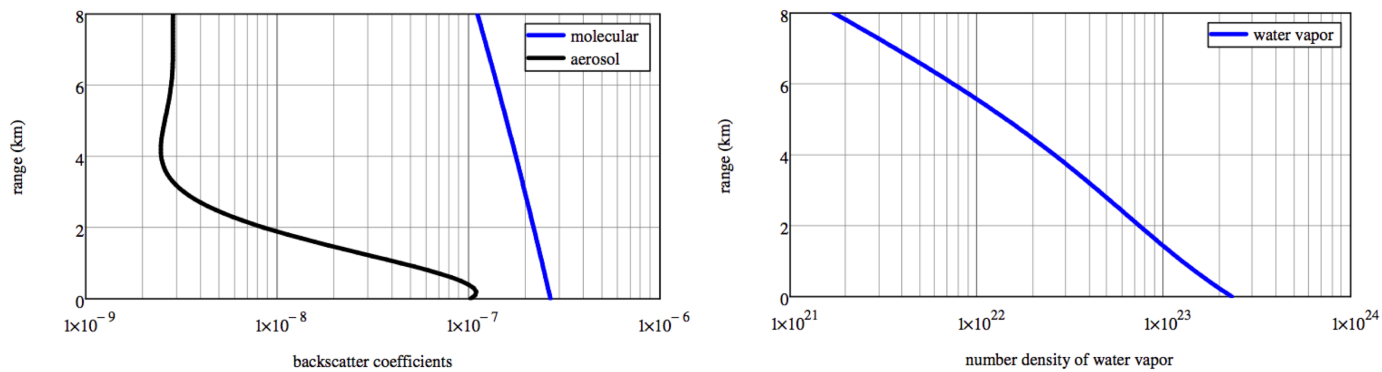

Figure 5. Backscatter coefficients (left panel) and water vapor number density (right panel) used in the performance model.

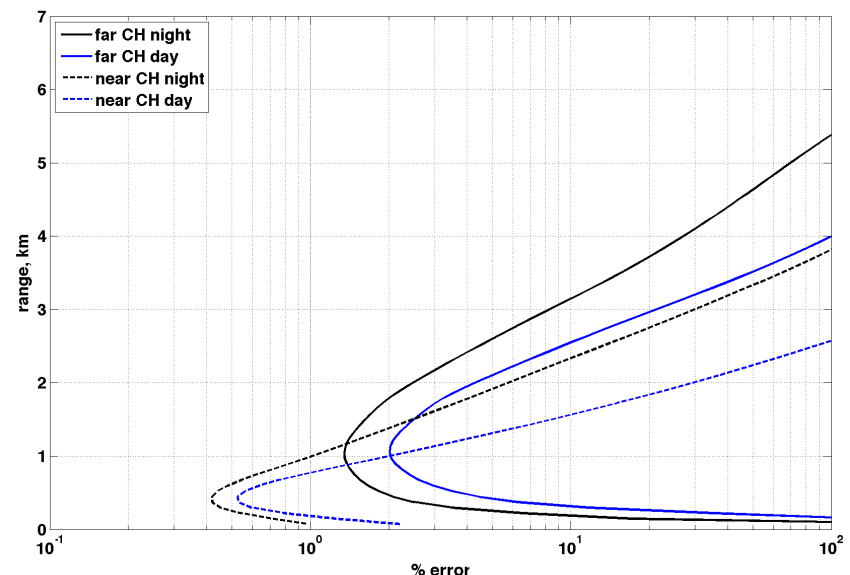

Figure 6. Performance estimate for day and night with $150 \mathrm{~m}$ range resolution and $10 \mathrm{~min}$ averaging for the near- and far-range channels for an online column OD of 1.5 . For a $10 \%$ error, the instrument has a typical daytime range of $\approx 2.5 \mathrm{~km}$ with this spatial and temporal averaging.

count rate in this channel would exceed the linear count rate of the photon-counting module. The maximum range can be marginally increased by tuning the online wavelength to provide a lower column OD although this introduces more error close the ground. A more effective method is to process the data above the boundary layer with a larger range bin size. As shown in Fig. 7, a two-way column OD of 0.6 and range bin of $600 \mathrm{~m}$ increases the maximum range of the instrument to about $4 \mathrm{~km}$ for a $10 \%$ error.

A practical limit to the maximum range for the groundbased DIAL results from the small differential optical depth associated with the water vapor absorption in the free troposphere. The differential optical depth, $\Delta \tau$, needed to retrieve the water vapor number density (Wulfmeyer and Walther, 2001a) is $\Delta \tau=n \sigma_{\text {on }} \Delta R \approx 0.03-0.1$, where $n$ is the water vapor number density, $\sigma_{\text {on }}$ is the absorption cross section at the online wavelength, and $R$ is the range bin size. For a maximum range bin size of $1 \mathrm{~km}$, the maximum range at which the water vapor profile can be retrieved approaches $7 \mathrm{~km}$.

Figure 8 shows the model results for a case with higher temporal resolutions of $1 \mathrm{~min}$ and $10 \mathrm{~s}$. The performance is

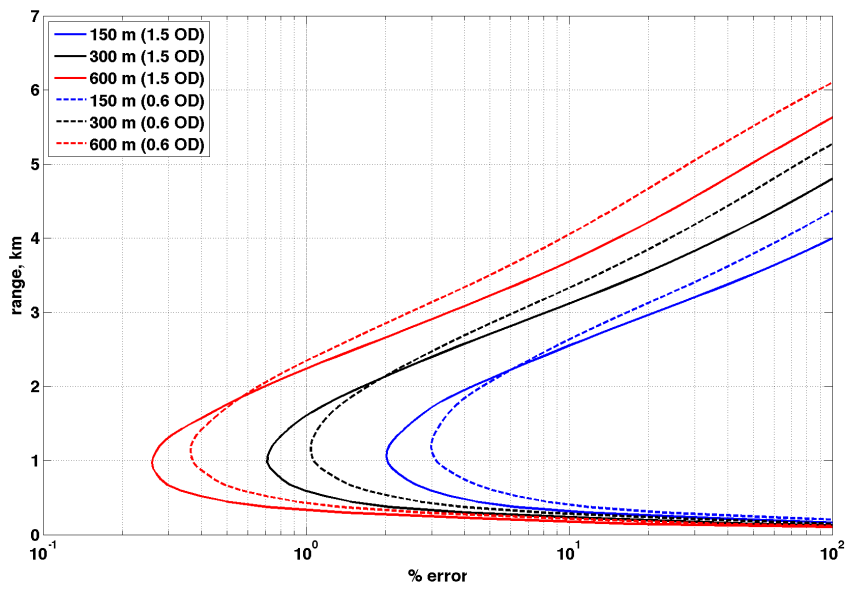

Figure 7. Daytime performance estimate for resolutions of $150 \mathrm{~m}$, $300 \mathrm{~m}$, and $600 \mathrm{~m}$ with integration time of $10 \mathrm{~min}$ and column optical depth at $5 \mathrm{~km}$ range of 0.6 and 1.5 .

expected to be useful for low-level boundary layer studies as the instrument can be operated with a resolution of $150 \mathrm{~m}$ and $1 \mathrm{~min}$ as the combined near- and far-range channels provide $<10 \%$ error for the lowest $2 \mathrm{~km}$. Since the data is collected at approximately $1 \mathrm{~Hz}$, any data set can be processed to high temporal resolution a posteriori. Improved spatial resolution would be possible by shortening the pulse length, for example to $75 \mathrm{~m}$, although the duration of the TSOA current pulse would be reduced in half from 1000 to $500 \mathrm{~ns}$ resulting in a pulse energy $2.6 \mu \mathrm{J}$. It is possible that the pulse energy could be increased from the standpoint of eye-safety restrictions; however, exceeding pulse currents of $10 \mathrm{~A}$ to the TSOA may adversely affect transmitter lifetimes. Therefore, reducing the pulse duration, and subsequently the power, to achieve higher spatial resolution needs to be considered more carefully.

Error from temperature uncertainty was not included in the analysis above. However, a temperature-sensitivity study of the absorption features used in this work was done by Nehrir et al. (2009), which showed the number density error as a function of temperature to be very low in the boundary layer and lower troposphere (typically 1 to 1.5 orders of magni- 


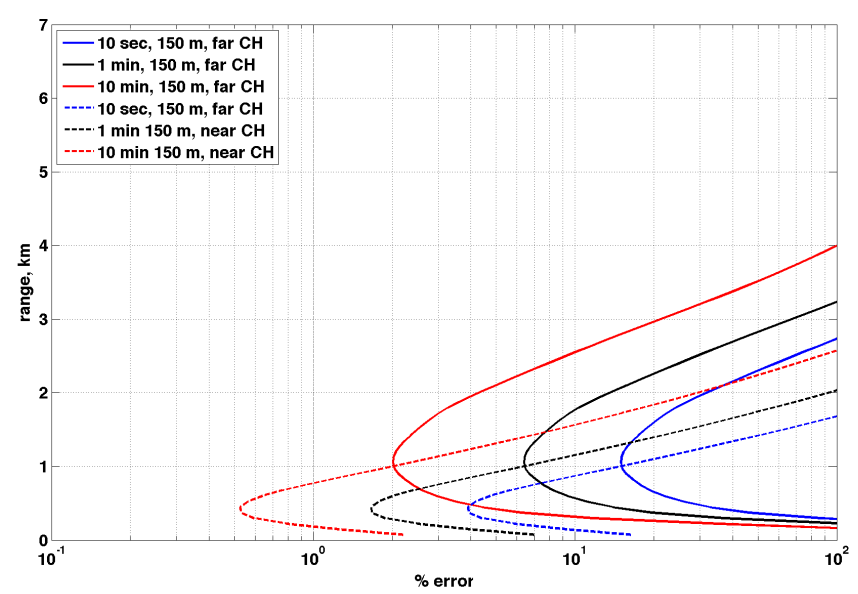

Figure 8. Daytime performance estimate in relative error (\%) for temporal resolutions of $10 \mathrm{~s}, 1 \mathrm{~min}$, and $10 \mathrm{~min}$ with a spatial resolution of $150 \mathrm{~m}$ for an online column OD of 1.5 The model results indicate that $1 \mathrm{~min}, 150 \mathrm{~m}$ resolution may be useful for boundary layer studies.

tude below the overall error in the water vapor measurement). Detector dark counts were also not included in this error analysis. The manufacturer specifies the dark count rate for the photon-detector modules used in this instrument at $250 \mathrm{Cs}^{-1}$. This is well below the measured nighttime background count rate of 2000 to $3000 \mathrm{Cs}^{-1}$ (note this can be seen in bottom panel of Fig. 11, which is discussed in the next section). The instrument does not have a detector-limited background but, instead, a signal-limited background that comes from backscattered photons from a range of $16.5 \mathrm{~km}$, which is the maximum range that can be reached with the system running at $9 \mathrm{kHz}$. The background overestimation leads to a small systematic bias. To minimize this bias, the instrument can be operated at a pulse repetition frequency of $7 \mathrm{kHz}$, extending the maximum range to $21 \mathrm{~km}$ so that the expected background count rate is comparable to the detector dark count rate. As a final caveat, Rayleigh broadening errors were not included in this analysis. Although beyond the scope of this effort, the most complete analysis that should account for this error is described by Ismail and Browell (1986).

\section{Data examples and intercomparisons}

The fourth-generation diode-laser-based DIAL was constructed at the NCAR lab in Boulder, $\mathrm{CO}$, in four phases between October 2013 and June 2014, implementing (1) the shared telescope, (2) two-channel receiver, (3) fast-switching transmitter and receiver, and (4) the optimization of the background suppressing filters and etalon. During the 8-month period of development, the instrument was run almost continuously with sonde comparisons done at each stage of the development. The completed instrument was moved to the
BAO for operation during the Front Range Air Pollution and Photochemistry Experiment (FRAPPE) between 1 July and 19 August 2014. Data from this field campaign are presented to demonstrate the capability of the WV-DIAL in continual operation for an extended period of time in a variety of atmospheric conditions.

For the results in this paper, the Voigt differential absorption cross section of the water molecule was calculated from parameters contained in the 2008 High-Resolution Transmission (HITRAN) molecular spectroscopic database (Rothman et al., 2009). Spectral parameters for the $\mathrm{H}_{2} \mathrm{O}$ molecule, including all isotopologues, from 824 to $832 \mathrm{~nm}$ (592 spectral lines in total) were used from the database to calculate the absorption cross section at the online and offline wavelengths. The numerically calculated Voigt absorption cross section is a convolution of the Lorentz and Doppler line shapes, which are a function of temperature and pressure. A standard atmosphere with surface $T=25 \mathrm{C}$ and $P=0.83 \mathrm{~atm}$ was used to correct the temperature- and pressure-dependent terms as a function of range. Previous MSU WV-DIAL prototypes and publications used the HITRAN 2000 database parameters, which does not include correction terms for air pressure shift. For those reported results (Nehrir et al., 2009, 2011, 2012; Repasky et al., 2013), only the main absorption line at $828.187 \mathrm{~nm}$ was corrected for the air pressure shift. The updated version of the database includes a parameter to correct for the air-broadened pressure shift of each line. The pressure shift corrections and other updated line parameters included the 2008 database and should provide more accurate results.

For the previous generations of MSU WV-DIAL prototypes, sonde comparisons were made for both day and night conditions as shown in Nehrir et al. $(2009,2011,2012)$ and Repasky et al. (2013). However, these instruments switched from online to offline at timescales of several seconds and could suffer from insufficient background suppression during daylight bright-cloud sky conditions. This made it difficult to achieve continuous water vapor measurements. Therefore, an important goal of this research effort was to demonstrate that the next-generation instrument was, indeed, capable of making accurate continuous water vapor measurements during daytime cloudy sky conditions, thereby operating over a more complete range of atmospheric conditions.

Sondes were released at the BAO in close proximity to the WV-DIAL instrument: 11 ozone radiosondes launched by NOAA from 10 to 16 July and 34 Vaisala RS92 radiosondes launched by the University of Wisconsin staff from 17 July to 17 August 2014. The period from 10 to 13 July had a high frequency of radiosondes launched. The relative backscatter measured by the WV-DIAL over the course of these 3 days is shown in the upper panel of Fig. 9 at 1 min temporal resolution. Frequent periods of daytime clouds are evident - shown in the figure as high backscatter regions (red) from 12:00 to 24:00 UTC on each day. The corresponding water vapor during this period is shown in the middle panel at a temporal resolution of $1 \mathrm{~min}$. The sonde launch times are indicated by 

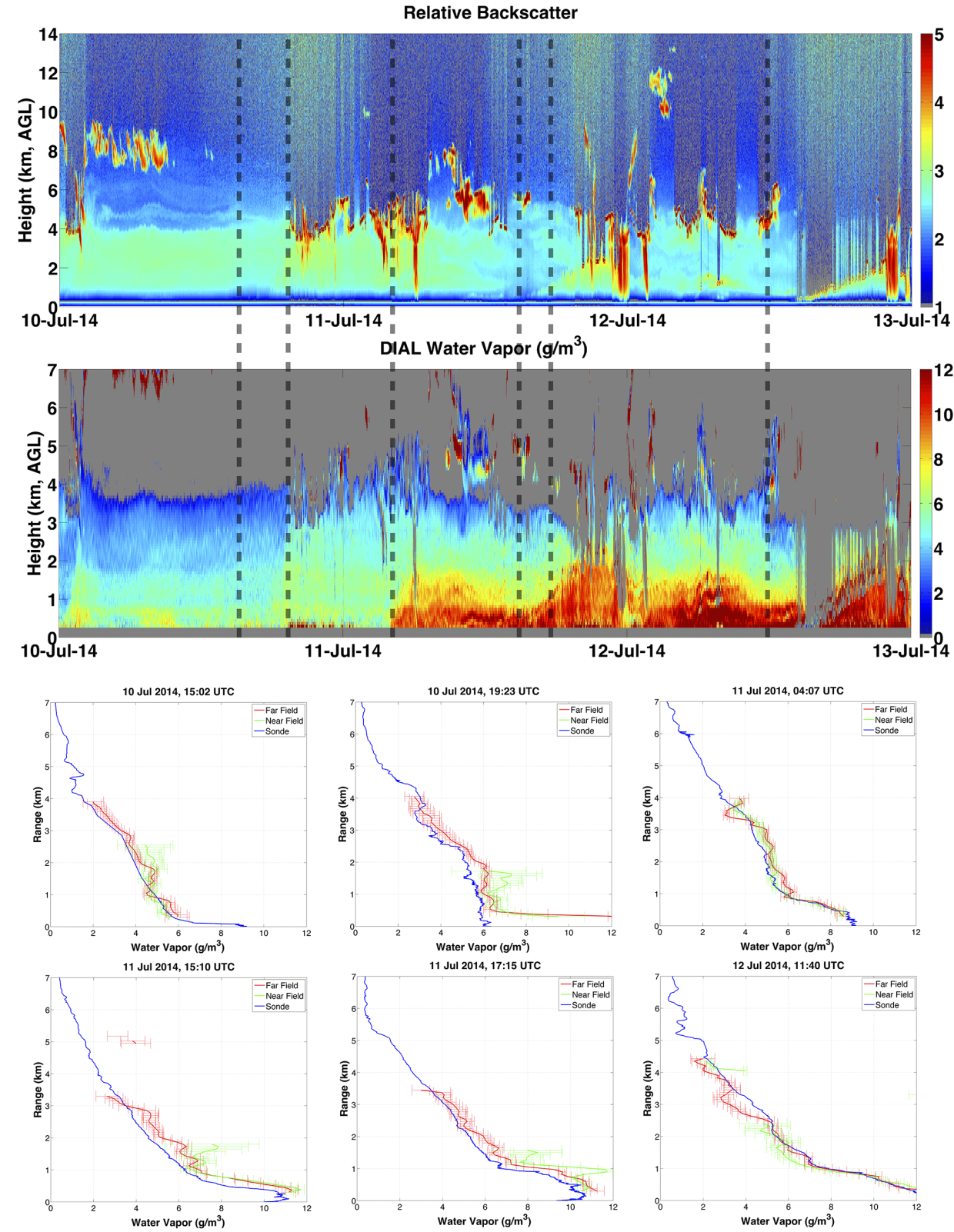

Figure 9. Top panel: $1 \mathrm{~min}, 150 \mathrm{~m}$ resolution relative backscatter from the range of $0-14 \mathrm{~km}$; middle panel: $1 \mathrm{~min}$, $150 \mathrm{~m}$ resolution water vapor in $\mathrm{g} \mathrm{m}^{-3} ; 300$ and $600 \mathrm{~m}$ smoothing were applied to the data from 2 to $3 \mathrm{~km}$ and above $3 \mathrm{~km}$, respectively. The dashed black lines overlain on the top and middle panels indicate times when sondes were launched. Bottom figures: individual water vapor concentration profiles for the sonde (blue) and WV-DIAL with $25 \mathrm{~min}$ average profiles for far-range (red) and near-range channels ( $\mathrm{green}$ ) in $\mathrm{g} \mathrm{m}^{-3}$.

the black lines overlaid on these two panels. The comparison profiles between the sondes (blue curves) and the WV-DIAL (near channel in green and far channel in red) are on the figure bottom. The measurements agree well with each other for the far-range channel from a lower range of $300 \mathrm{~m} \mathrm{ex}$ tending to $3-4 \mathrm{~km}$ depending on atmospheric conditions. The near-field channel provides a comparable measurement of water vapor from $300 \mathrm{~m}$ to $1-2 \mathrm{~km}$ during the daytime. The only nighttime launch in this series on 11 July at 04:07 UTC
(22:07 LT on 10 July) demonstrates that the near-field channel extends to the same range as the far-field channel without the solar background. The $4 \mathrm{~km}$ range limit was imposed by clouds in this particular case. The increasing water vapor in the lower atmosphere - from 6 to $>12 \mathrm{~g} \mathrm{~m}^{-3}$ - over the 3 day period was roughly captured by the sonde profiles. However, the continuous WV-DIAL time series offers an accurate and more detailed picture of the atmospheric water vapor distribution. For example, the organization of filaments of water 


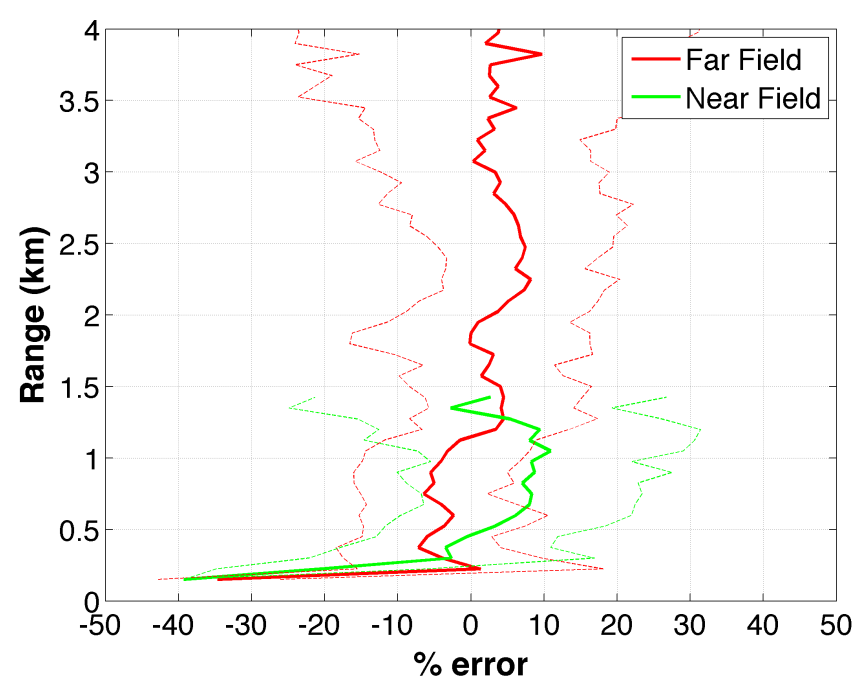

Figure 10. Sonde- to DIAL-measured water vapor in percent error. The mean (solid line) and SD (dashed line) percent errors are shown for all 45 sondes launched from 10 July through 19 August. The spatial resolution of the DIAL profiles are $150 \mathrm{~m}$ below $2 \mathrm{~km}$ and $600 \mathrm{~m}$ above $2 \mathrm{~km}$. The DIAL profiles were processed with at $1 \mathrm{~min}$ temporal resolution and averaged for $25 \mathrm{~min}$ starting at the sonde launch time.

vapor with wave-like structure is evident in the lower $2 \mathrm{~km}$ between 12:00 UTC on 11 July to 12:00 UTC on 12 July.

During the FRAPPE campaign, 45 sondes were released (43 daytime sondes and 2 nighttime) between 10 July and 18 August 2014. A plot of the percent error of WV-DIALmeasured water vapor concentration compared to the sondes is shown in Fig. 10. A spatial averaging of $150 \mathrm{~m}$ was used (with $600 \mathrm{~m}$ smoothing applied to the data above $2 \mathrm{~km}$ ) with $1 \mathrm{~min}$ temporal resolution profiles averaged for $25 \mathrm{~min}$ starting at the sonde launch time. The mean relative error is less than $10 \%$ from the lowest gate at approximately $300 \mathrm{~m}$ to $4 \mathrm{~km}$ for the far-range channel. For this predominantly daytime set of comparisons, the near-range channel provides a slightly lower error below $500 \mathrm{~m}$ range. The SD is $\approx 10 \%$ above the mean at the surface and increases to $\approx 20 \%$ at $1.5 \mathrm{~km}$ for the near-range channel and $4 \mathrm{~km}$ for the far-range channel. A small number of comparisons were greater than three times the SDs and were removed as outliers from the calculation of the mean. There are several potential reasons for discrepancies between the absolute humidity measured by the WV-DIAL and the radiosondes. The sondes inevitably drift with the wind as they rise and are generally not in close proximity to the lidar beam. Spatiotemporal matching was not employed at this phase in the analysis as done in Vogelmann et al. (2011). Additionally, a strong wet bias often occurs in the WV-DIAL at the cloud edges, which is not filtered out in the current post-processing - as evidenced in the time vs. height profiles shown in Fig. 9. These spatially localized biases can dominate the statistics given the relatively small number of comparisons. More work will be done to remove these small regions of bias in the future. Finally, there may be systematic instrument bias or errors within the HITRAN 2008 molecular spectroscopic database parameters used to calculate the differential absorption cross section of the water molecule. To improve performance, detailed studies of the molecular spectroscopic parameters have been performed for other DIAL systems - such as those presented by Grossmann and Browell (1989), Lisak et al. (2009), and Ponsardin and Browell (1997) - and may be required to improve the accuracy of this system. With these caveats, it seems reasonable to claim that the measurements of water vapor provided by the WV-DIAL agree well (with less than $10 \%$ mean error) with the radiosonde measurements of water vapor over a wide range of atmospheric conditions.

The instrument was operated unattended for 50 continuous days during the FRAPPE field campaign from a mobile laboratory container with approximately $\pm 5^{\circ} \mathrm{C}$ temperature stability. The device was aligned once (at setup only) and there was no detectable degradation in performance during the project or evidence of temperature cycling in the data. The instrument operated reliably, providing $>95 \%$ data coverage. A subset - a 2-week period from 1 to 14 July 2014 of near continuous data is shown in Fig. 11. The top panel shows the relative backscatter at $1 \mathrm{~min}, 150 \mathrm{~m}$ vertical resolution for distances between 0 to $14 \mathrm{~km}$ range. The image is a composite of the near- and far-range channels below $3 \mathrm{~km}$ and the far-range channel only above $3 \mathrm{~km}$. The second panel from the top shows the measured absolute humidity in $\mathrm{g} \mathrm{m}^{-3}$ at $10 \mathrm{~min}, 150 \mathrm{~m}$ vertical resolution from 0 to $7 \mathrm{~km}$ (data from the near-range channel). This unique image of the water vapor distribution in the lower atmosphere is only possible with high-vertical-resolution continuous profiling. The second panel from bottom shows the measured two-way column optical depth at $2.5 \mathrm{~km}$ (blue) and $5.0 \mathrm{~km}$ (black) range for the far-range channel for this time period. The wavelength of the instrument was not adjusted for this time span, so this is representative of the natural atmospheric variability and can be converted to a water vapor column content and used to compare with other instrumentation. The bottom panel shows the measured background in counts per second $\left(\mathrm{C} \mathrm{s}^{-1}\right)$ for the near-range (red) and far-range (black) channels. To measure water vapor accurately, the photon count rates need to be within the linear response range of the photon-counting modules - below $5 \mathrm{MCs}^{-1}$ for the modules used in this instrument. As seen in the plot, the far-range channel has a maximum count rate of $1 \mathrm{MC} \mathrm{s}^{-1}$ during the brightest of atmospheric conditions. This is a significant improvement over the previous-generation receivers where the count rate would be in excess of $10 \mathrm{MCs}^{-1}$ under daytime cloudy conditions, as shown in Fig. 9 of Repasky et al. (2013). The near-range channel, with its wide field-of view and one less filtering stage, approaches $100 \mathrm{MC} \mathrm{s}^{-1}$ under these bright conditions and is not capable of accurately measuring water vapor during these time periods. 

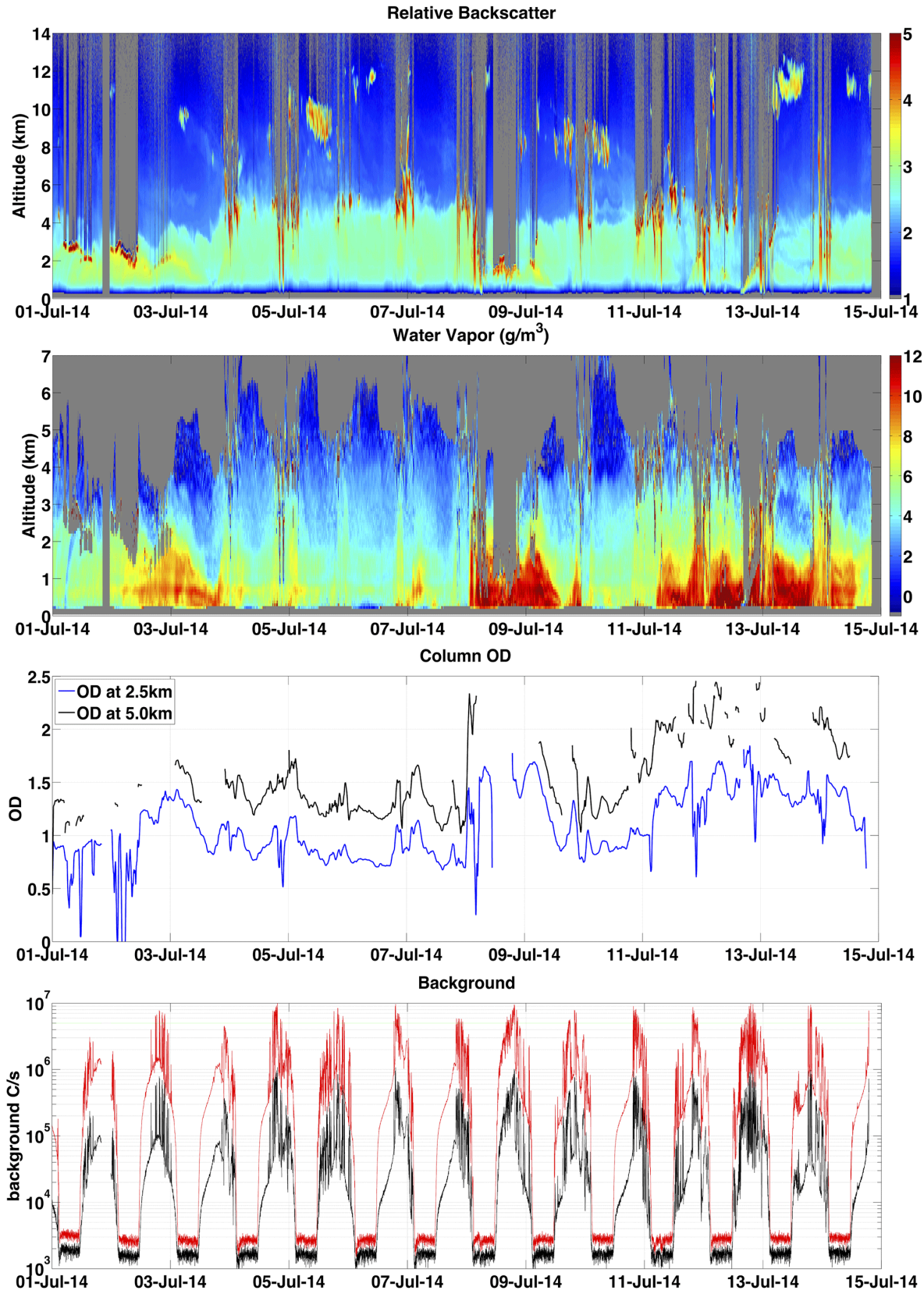

Figure 11. Two weeks of near continuous data collected 1-14 July 2014. Top panel: $1 \mathrm{~min}, 150 \mathrm{~m}$ resolution relative backscatter from 0 to $14 \mathrm{~km}$ range for the far-range channel; second panel from top: $10 \mathrm{~min}, 150 \mathrm{~m}$ resolution water vapor in $\mathrm{g} \mathrm{m}^{-3}$ from 0 to $7 \mathrm{~km} \mathrm{range} \mathrm{for} \mathrm{the}$ far-range channel - with 300 and $600 \mathrm{~m}$ smoothing applied to the data from 3 to $5.25 \mathrm{~km}$ and above $5.25 \mathrm{~km}$, respectively, second panel from bottom: measured two-way optical depth at $2.5 \mathrm{~km}$ (blue) and $5.0 \mathrm{~km}$ (black) range for the far-range channel; and bottom panel: background in counts per second $\left(\mathrm{C} \mathrm{s}^{-1}\right)$ for the near-range (red) and far-range (black) channels.

At FRAPPE, the diode-laser-based WV-DIAL was colocated with several active and passive remote sensing instruments. A quantitative comparison between other instruments is beyond the scope of this instrument paper. However, a detailed intercomparison study highlighting the different spatial and temporal resolutions between the WV-DIAL and the AERI using the FRAPPE data set is planned for a separate paper. In the future, more focus is needed on improved algorithms to process the data (e.g., masking the data at cloud boundaries, improving low signal-to-noise thresholds, and allowing for variable temporal and spatial resolution with range). Also, real-time algorithms are desired to adjust the online wavelength (and corresponding offline and etalon temperature) to maintain optimal optical depth 
and performance for extended autonomous field operations. Tests should be performed at shorter pulse duration to investigate reducing the lowest usable gate a.g.l. to below $300 \mathrm{~m}$. Currently the transmitter is capable of higher output power and is limited by eye-safety regulations; the shared transmitreceive path could be redesigned (albeit with some added complexity) to allow the beam to be expanded to the full telescope diameter, which would allow higher output power and improved performance. Also, asynchronous wavelength switching could be tested as a means to improve performance without increasing the transmitted power level. The nearrange channel could be modified to have a slightly reduced field-of-view to avoid nonlinear detector response at high count rates during bright-cloud conditions. Finally, a more portable environmental enclosure should be designed and constructed to make fielding the instrument easier and less costly in the future.

\section{Conclusions}

A field-deployable, high-vertical-resolution water vapor profiling instrument has been constructed and tested. It was built on the success of previous diode-laser-based prototypes and advances the technology to provide measurements over a broadened range of atmospheric conditions. The optomechanically stable, eye-safe design provides improved temporal resolution, reduced errors at short range, improved daytime performance, and reduced errors when clouds are present. This next-generation water vapor profiler has been demonstrated to be capable of reliable operation in the field and shown to provide data that compare favorably with sondes over a wide range of atmospheric conditions. The instrument has the potential to provide a priority observation needed for national mesoscale weather observation networks, the National Weather Service, and other federal agencies. The demonstrated performance and reliability suggest that this technology may be suitable for a future network of water vapor profiling instruments.

Acknowledgements. The authors affiliated with Montana State University would like to acknowledge the support of the National Science Foundation grant number 1206166. The National Center for Atmospheric Research is sponsored by the National Science Foundation. Component manufactures were included to help other researchers reproduce this work but are not meant as an endorsement by the authors. The NCAR authors thank Rich Erickson for technician support and Richard E. Carbone and Tammy M. Weckwerth for helpful discussions pertaining to the atmospheric science applications and internal review of the paper.

Edited by: G. Ehret

\section{References}

American National Standard Institute: American National Standard for Safe Use of Lasers, in: Z136.1-2007, edited by Laser Institute of America, Orlando, FL, USA, 2007.

Behrendt, A., Wulfmeyer, V., Riede, A., Wagner, G., Pal, S., Bauer, H., and Späth, F.: Scanning differential absorption lidar for 3D observations of the atmospheric humidity field, in: International Laser Radar Conference, p. 3, St. Petersburg, Russia, 2010.

Bösenberg, J. and Linné, H.: Continuous Ground-Based Water Vapour Profiling using DIAL, in: International Laser Radar Conference, pp. 679-682, Nara City, Japan, 2006.

Ertel, K., Linné, H., and Bösenberg, J.: Injection-seeded pulsed Ti:sapphire laser with novel stabilization scheme and capability of dual-wavelength operation, Appl. Optics, 44, 5120-5126, 2005.

Feltz, W., Smith, W., Howell, H., Knuteson, R., H., W., and Revercomb, H.: Near-continuous profiling of temperature, moisture, and atmospheric stability using the atmospheric emitted radiance interferometer (AERI), J. Appl. Meteorol., 42, 584-597, 2003.

Goldsmith, J. E., Forest, M., Blair, H., Bisson, S. E., and Turner., D. D.: Turn-Key Raman Lidar for Profiling Atmospheric Water Vapor, Clouds, and Aerosols, Appl. Optics, 37, 4979, doi:10.1364/AO.37.004979, 1998.

Grossmann, B. E. and Browell, E. V.: Spectroscopy of water-vapor in the $720 \mathrm{~nm}$ wavelength region - line strengths, self-induced pressure broadenings and shifts, and temperature dependence of linewidths and shifts, J. Mol. Spectrosc., 136, 264-294, 1989:.

Ismail, S. and Browell, E. V.: Influence of Rayleigh-Doppler Broadening on the Selection of H2O DIAL System Parameters, in: International Laser Radar Conference, p. 3, Toronto, Canada, 1986.

Knuteson, R., Revercomb, H., Best, F., Ciganovich, N., Dedecker, R., Dirkx, T., Ellington, S., Feltz, W., Garcia, R., Howell, H., Smith, W., Short, J., and Tobin, D.: Atmospheric emitted radiance interferometer. part II: Instrument performance, J. Atmos. Ocean. Technol., 21, 1777-1789, 2004a.

Knuteson, R., Revercomb, H., Best, F., Ciganovich, N., Dedecker, R., Dirkx, T. P., Ellington, S., Feltz, W., Garcia, R., Howell, H., Smith, W., Short, J., and Tobin, D.: Atmospheric emitted radiance interferometer. Part I: Instrument Design, J. Atmos. Ocean. Technol., 21, 1763-1776, 2004b.

Lisak, D., Havey, D. K., and Hodges, J. T.: Spectroscopic line parameters of water vapor for rotation-vibration transitions near 7180 cm-1, Phys. Rev. A, 79, 1-10, 2009.

Machol, J. L., Ayers, T., Schwenz, K. T., Koenig, K. W., Hardesty, R. M., Senff, C., Krainak, M. A., Abshire, J. B., Bravo, H. E., and Sandberg, S. P.: Preliminary Measurements with an Automated Compact Differential Absorption Lidar for the Profiling of Water Vapor, Appl. Optics, 43, 3110-3121, doi:10.1364/AO.43.003110, 2004.

National Research Council: Observing Weather and Climate from the Ground Up: A Nationwide Network of Networks, The National Academies Press, Washington, DC, 2009.

National Research Council: When Weather Matters: Science and Service to Meet Critical Societal Needs, The National Academies Press, Washington, DC, 2010.

NCAR Atmospheric Chemistry Division: FRAPPÉ - Front Range Air Pollution and Photochemistry Experiment, available at: https: //www2.acd.ucar.edu/frappe (last access: 1 October 2014), 2014. 
Nehrir, A. R.: Development of an Eye-Safe Diode-Laser-Based Micro-Pulse Differential Absorption Lidar (MP- DIAL) for Atmospheric Water vapor and Aerosol Studies, Ph.D. thesis, Montana State University, 2011.

Nehrir, A. R., Repasky, K. S., Carlsten, J. L., Obland, M. D., and Shaw, J. A.: Water Vapor Profiling Using a Widely Tunable, Amplified Diode-Laser-Based Differential Absorption Lidar (DIAL), J. Atmos. Ocean. Technol., 26, 733-745, doi:10.1175/2008JTECHA1201.1, 2009.

Nehrir, A. R., Repasky, K. S., and Carlsten, J. L.: Eye-Safe Diode-Laser-Based Micropulse Differential Absorption Lidar (DIAL) for Water Vapor Profiling in the Lower Troposphere, J. Atmos. Ocean. Technol., 28, 131-147, doi:10.1175/2010JTECHA1452.1, 2011.

Nehrir, A. R., Repasky, K. S., and Carlsten, J. L.: Micropulse water vapor differential absorption lidar: transmitter design and performance, Optics express, 20, 137-151, 2012.

NOAA Physical Sciences Division: The Boulder Atmospheric Observatory, available at: http://www.esrl.noaa.gov/psd/technology/ bao/ (last access: 1 October 2014), 2014.

Pike, E. and Sabatier, P.: Scattering, Two-Volume Set: Scattering and inverse scattering in Pure and Applied Science, Elsevier Science, 2001.

Ponsardin, P. L. and Browell, E. V.: Measurements of H216O Linestrengths and Air-Induced Broadenings and Shifts in the 815 nm Spectral Region, J. Molecular Spectr., 185, 58-70, 1997.

Reagan, J. A., Cooley, T. W., and Shaw, J. A.: Prospects for an economical, eye-safe water vapor LIDAR., in: International Geoscience and Remote Sensing Symposium, Better Understanding of Earth Environment, 872-874, IEEE, Kogakuin University, Tokyo, Japan, doi:10.1109/IGARSS.1993.322198, 1993.

Repasky, K., Moen, D., Spuler, S., Nehrir, A., and Carlsten, J.: Progress towards an Autonomous Field Deployable DiodeLaser-Based Differential Absorption Lidar (DIAL) for Profiling Water Vapor in the Lower Troposphere, Remote Sens., 5, 62416259, doi:10.3390/rs5126241, 2013.

Rothman, L., Gordon, I., Barbe, A., Benner, D., Bernath, P., Birk, M., Boudon, V., Brown, L., Campargue, A., Champion, J.-P., Chance, K., Coudert, L., Dana, V., Devi, V., Fally, S., Flaud, J.M., Gamache, R., Goldman, a., Jacquemart, D., Kleiner, I., Lacome, N., Lafferty, W., Mandin, J.-Y., Massie, S., Mikhailenko, S., Miller, C., Moazzen-Ahmadi, N., Naumenko, O., Nikitin, A. V., Orphal, J., Perevalov, V., Perrin, A., Predoi-Cross, A., Rinsland, C., Rotger, M., Šimečková, M., Smith, M., Sung, K., Tashkun, S., Tennyson, J., Toth, R., Vandaele, A. C., and Vander Auwera, J.: The HITRAN 2008 molecular spectroscopic database, J. Quant. Spectr. Radiat. Trans., 110, 533-572, doi:10.1016/j.jqsrt.2009.02.013, 2009.
Turner, D. D. and Löhnert, U.: Information Content and Uncertainties in Thermodynamic Profiles and Liquid Cloud Properties Retrieved from the Ground-Based Atmospheric Emitted Radiance Interferometer (AERI), J. Appl. Meteorol. Climatol., 53, 752771, 2014.

Turner, D. D., Ferrare, R. A., Brasseur, L. A. H., Feltz, W. F., and Tooman, T. P.: Automated Retrievals of Water Vapor and Aerosol Profiles from an Operational Raman Lidar, J. Atmos. Ocean. Technol., 19, 37-50, 2002.

Vogelmann, H. and Trickl, T.: Wide-range sounding of freetropospheric water vapor with a differential-absorption lidar (DIAL) at a high-altitude station, Appl. Optics, 47, 2116, doi:10.1364/AO.47.002116, 2008.

Vogelmann, H., Sussmann, R., Trickl, T., and Borsdorff, T.: Intercomparison of atmospheric water vapor soundings from the differential absorption lidar (DIAL) and the solar FTIR system on Mt. Zugspitze, Atmos. Meas. Tech., 4, 835-841, doi:10.5194/amt-4-835-2011, 2011.

Wulfmeyer, V. and Bösenberg, J.: Ground-based differential absorption lidar for water-vapor profiling: assessment of accuracy, resolution and meteorological applications, Appl. Optics, 37, 38253844, 1998.

Wulfmeyer, V. and Walther, C.: Future performance of a groundbased and airborne water-vapor differential absorption lidar. I. Overview and theory, Appl. Optics, 40, 5304-5320, doi:10.1364/AO.40.005304, 2001a.

Wulfmeyer, V. and Walther, C.: Future performance of groundbased and airborne water-vapor differential absorption lidar. II. Simulations of the precision of a near-infrared, high-power system, Appl. Optics, 40, 5321-5336, 2001b. 